\title{
POROSIDADE DE KIRKENDALL EM JUNTAS SOLDADAS DISSIMILARES ENTRE LIGA FE-CR-AL E AÇO INOXIDÁVEL AISI 310 APÓS TRATAMENTO ISOTÉRMICO A $1150^{\circ} \mathrm{C}$ AO AR *
}

André de Albuquerque Vicente ${ }^{1}$ Giovani Jonas de Lima² Débora Arruda Cabral ${ }^{3}$ Carlos Alberto Faggian ${ }^{4}$ Tiago Felipe de Abreu Santos ${ }^{5}$ Jorge Alberto Soares Tenório ${ }^{6}$

\section{Resumo}

Observou-se porosidade de Kirkendall em juntas soldadas dissimilares de liga Fe-CrAl do tipo 23Cr-7Al, e aço inoxidável austenítico AISI 310 (25Cr-20Ni). Utilizou-se como consumível de soldagem a própria liga Fe-Cr-Al. O processo de soldagem utilizado foi o GTAW. Caracterizaram-se 3 conjuntos de corpos de prova soldados com diferentes energias de soldagem, antes e após o tratamento isotérmico a $1150^{\circ} \mathrm{C}$ por 936 horas ao ar. Nos corpos de prova tratados termicamente, observouse a formação de poros bem como significativas variações dos teores de Al nos metais depositados e formação de camada protetora de alumina nas superfícies oxidadas.

Palavras-chave: GTAW, Poros de Kirkendall; Ligas Fe-Cr-Al; AISI 310.

\section{KIRKENDALL POROSITY IN DISSIMILAR WELDING JOINTS BETWEEN FE-CR- AL ALLOY AND STAINLESS STEEL AISI 310 AFTER ISOTHERMIC HEAT TREATMENT AT $1150^{\circ} \mathrm{C}$ IN AIR}

\begin{abstract}
Kirkendall porosity was observed in dissimilar welded joints of $\mathrm{Fe}-\mathrm{Cr}$-Al alloy (23Cr$7 \mathrm{AI}$ ) and AISI 310 austenitic stainless steel $(25 \mathrm{Cr}-20 \mathrm{Ni})$. The Fe-Cr-Al alloy was used as the welding consumable. The welding process used was GTAW. Three sets of test specimens welded with different welding energies were characterized, before and after the isothermal heat treatment at $1150^{\circ} \mathrm{C}$ for 936 hours in air. In the heat treated specimens, pore formation was observed as well as significant variations of Al contents in all-welded metals and formation of protective layer of alumina on the oxidized surfaces.
\end{abstract}

Keywords: GTAW, Kirkendall Porosity, Alloys Fe-Cr-AI, AISI 310.

\footnotetext{
Doutorando do Departamento de Engenharia Química da EPUSP.

Especialista em Engenharia de Soldagem pelo PECE-EPUSP.

Engenheranda do Departamento de Engenharia Metalúrgica e de Materiais da EPUSP.

Mestrando do Departamento de Engenharia Química da EPUSP.

Professor Adjunto do Departamento de Engenharia Mecânica da UFPE.

Professor Titular do Departamento de Engenharia Química da EPUSP.
} 


\section{INTRODUÇÃO}

Pode-se dividir os estudos de difusão em metais puros, ligas homogêneas e ligas heterogêneas. No estudo para ligas heterogêneas, a compreensão dos mecanismos de difusão pode ser em escala macroscópica, avaliando-se as variações de concentração dos solutos. [1,2]

A primeira lei de Fick relaciona a mudança de concentração de um soluto localizado em um plano A e que migra para um plano $B$ de menor concentração, redistribuindo de forma homogênea a concentração do soluto. $[1,2$,

$$
(\mathrm{dn} / \mathrm{dt})=-\mathrm{D} .(\mathrm{dC} / \mathrm{dx}) \quad \text { Equação } 1[1,2]
$$

Onde $\mathrm{D}$ é o coeficiente de difusão, que varia conforme a temperatura e a composição do soluto. [2]

Os mecanismos de difusão para um metal puro são definidos como intersticial, que ocorre sem a troca de posições dos átomos dos reticulados e substitucional, onde ocorre a troca de posições dos átomos no reticulado, preferencialmente onde existem lacunas. [1-5]

Para um sistema de ligas com elementos A e B com diferentes coeficientes de difusão, comparando com os metais puros, o mecanismo de difusão por lacunas requer menor energia de difusão. Kirkendall demonstrou em seus experimentos com ligas $\mathrm{Cu}-\mathrm{Zn}$ que o Zinco difundiu com uma velocidade mais elevada que o Cobre. Para essa verificação, foi utilizado um marcador inerte para referência, que foi deslocado no sentido de difusão do Zn. [1-5]

O grande fluxo de lacunas causado, por exemplo, por pares de elementos com grande gradiente de concentração podem se condensar em poros, os chamados poros de Kirkendall. [5,6]

Vários tipos de materiais ferríticos foram desenvolvidos para possuir resistência à corrosão e a oxidação em altas temperaturas. Eles são caracterizados por possuir baixo teor de carbono e alto teor de cromo [7] e como o cromo é um estabilizador de ferrita ele não pode ser endurecido por tratamento térmico. A excelente resistência a oxidação das ligas Fe-Cr-Al é devida a formação de um filme protetivo $\left(\mathrm{Al}_{2} \mathrm{O}_{3}\right)$. Essas ligas são utilizadas na fabricação de resistências elétricas, e possuem um maior custo efetivo que o aço inoxidável austenítico tornando-se muito caro em algumas aplicações. Quando é exigida maior resistência mecânica devem-se utilizar aços austenítico, ou em alguns casos ligas Cromo-Níquel. [7]

Apesar do aumento da temperatura acelerar o processo de perda de camada, mesmo quando em operação em temperaturas de até $1400^{\circ} \mathrm{C}$ (de 100 a $200^{\circ} \mathrm{C}$ abaixo do ponto de fusão), uma liga com 15 a $30 \%$ de cromo e ao menos $5 \%$ de alumínio, perde somente de 0,5 à 1,0 gramas por metro quadrado por hora, o que é menos que as perdas registradas em aços cromo níquel resistentes ao calor. O filme de óxido que forma-se em temperaturas abaixo de $700^{\circ} \mathrm{C}$ constitui-se de óxido de ferro, cromo e alumínio aproximadamente na mesma proporção que os elementos de liga, entretanto a extensão da escala foi pequena. $O$ filme formado em ligas ricas em alumínio e submetido a temperaturas maiores que $700^{\circ} \mathrm{C}$ apresentam cor cinza claro, e são normalmente compostas por puro óxido. Kornilov reportou que uma liga contendo $25 \%$ de cromo, $5 \%$ de alumínio após a exposição à uma temperatura de $1200^{\circ} \mathrm{C}$ por 240 horas resultou em $98,72 \%$ de $\mathrm{Al}_{2} \mathrm{O}_{3}, 0,80 \% \mathrm{Fe}_{3} \mathrm{O}_{4}$ e $0,68 \%$ de $\mathrm{Cr}_{2} \mathrm{O}_{3}$.[8] 
Mesmo após prolongados períodos de exposição o teor de cromo das ligas $\mathrm{Fe}-\mathrm{Cr}$-Al permanecem constantes, segundo Case \& Van Horn [8]. A formação da camada de passivação (óxido) depende do teor de alumínio da liga. Em ligas com baixo teor de alumínio a queda pode chegar a $60 \%$, enquanto em ligas com alto teor a perda média de alumínio é muito baixa. [8]

A formação da camada de óxido em alta temperatura ocorre conforme as seguintes reações:

$$
\begin{array}{ll}
2(\mathrm{Al}, \mathrm{Cr}, \mathrm{Fe})+4,5 \mathrm{O}_{2} \rightarrow \mathrm{Al}_{2} \mathrm{O}_{3}+\mathrm{Cr}_{2} \mathrm{O}_{3}+\mathrm{Fe}_{2} \mathrm{O}_{3} & \text { (Equação 2) } \\
\mathrm{Cr}_{2} \mathrm{O}_{3}+2 \mathrm{Al} \rightarrow \mathrm{Al}_{2} \mathrm{O}_{3}+2 \mathrm{Cr} & \text { (Equação 3) } \\
\mathrm{Fe}_{2} \mathrm{O}_{3}+2 \mathrm{Al} \rightarrow \mathrm{Al}_{2} \mathrm{O}_{3}+2 \mathrm{Fe} & \text { (Equação 4) }
\end{array}
$$

Em temperaturas até $700^{\circ} \mathrm{C}$ a carepa consiste em uma solução solida de três óxidos. Este processo é controlado pela equação 2. Quando a temperatura é elevada acima de $700^{\circ} \mathrm{C}$, as reações aluminotérmicas representadas pelas equações 3 e 4, ocorrem simultaneamente com reação representada pela equação1. Desta maneira a espessura do filme óxido permanece em crescimento e tanto a cromita $\mathrm{Cr}_{2} \mathrm{O}_{3}$ quanto a hematita $\mathrm{Fe}_{2} \mathrm{O}_{3}$ são reduzidas formando alumina $\mathrm{Al}_{2} \mathrm{O}_{3}$. [8]

\section{MATERIAIS E MÉTODOS}

\subsection{Montagem dos corpos de prova:}

Foram soldados três corpos de prova com parâmetros de soldagem distintos, correspondentes às peças utilizadas nos fornos. Utilizou-se uma barra redonda de aço inoxidável tipo AISI 310 de dimensões $\varnothing 9,5 \times 100 \mathrm{~mm}$ de comprimento e arames de uma liga Fe-Cr-Al (liga Kanthal A1) de dimensões $\varnothing 4,0 \times 100 \mathrm{~mm}$ de comprimento. A figura 1 mostra os detalhes dimensionais desse corpo de prova.

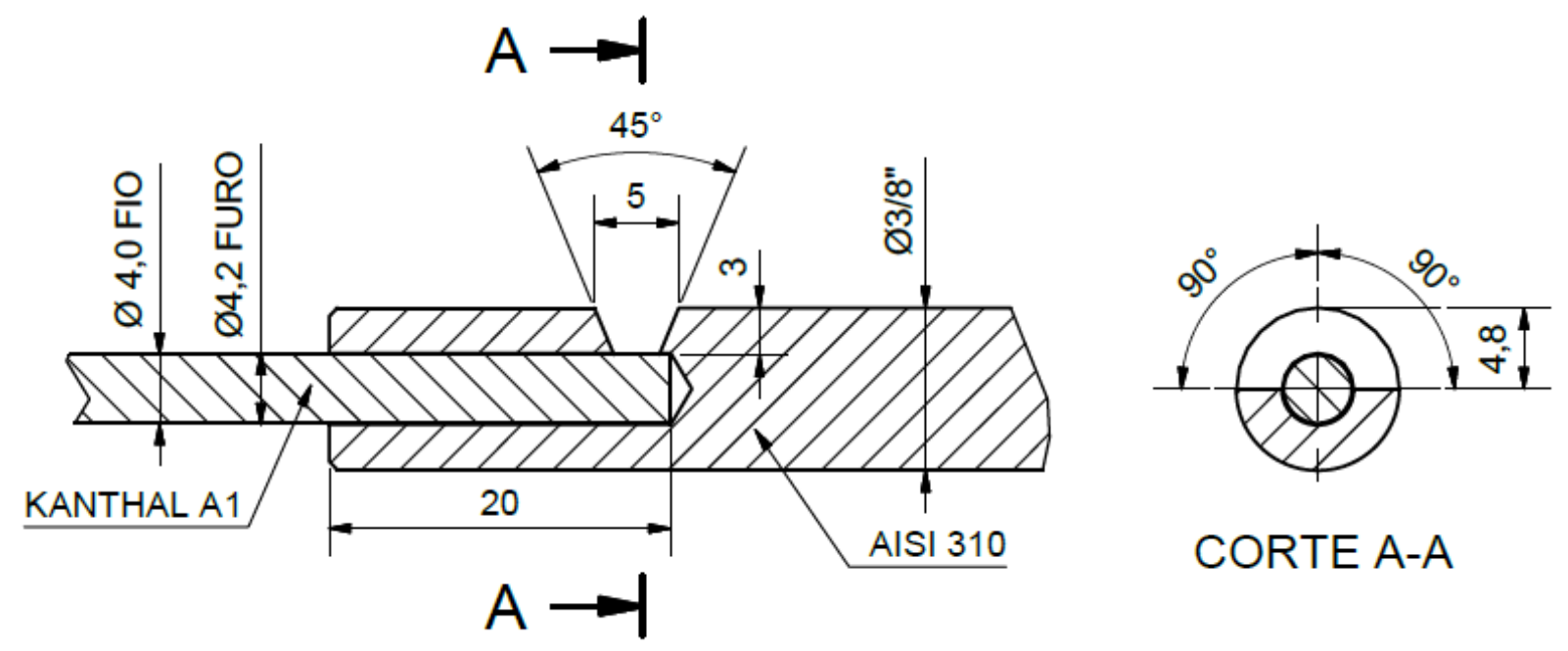

Figura 1 - Dimensional e detalhes de montagem do corpo de prova cilíndrico.

A soldagem foi realizada no chanfro aberto com ângulo de $45^{\circ}$ que permitiu o acesso da extremidade do arame. Utilizou-se o processo GTAW (também conhecido por TIG). O gás de proteção utilizado foi Argônio puro e a fonte de soldagem, de corrente constante. A corrente $(A)$ e a velocidade de soldagem $(\mathrm{mm} / \mathrm{s})$ foram monitoradas durante a soldagem para o posterior cálculo de energia de soldagem.

A soldagem dos corpos de prova foi realizada na posição plana. A tabela 1 lista os parâmetros de soldagem dos corpos de prova. 
Tabela 1 - Parâmetros de soldagem dos corpos de prova.

\begin{tabular}{|c|c|c|c|c|c|}
\hline $\begin{array}{c}\text { Corpo de } \\
\text { Prova }\end{array}$ & Polaridade & Corrente (A) & Tensão (V) & $\begin{array}{c}\text { Velocidade de } \\
\text { Soldagem (mm/s) }\end{array}$ & $\begin{array}{c}\text { Energia de } \\
\text { Soldagem (kJ/mm) }\end{array}$ \\
\hline $\mathbf{1}$ & CC- & 60,0 & 9,8 & 1,0 & 0,59 \\
\hline $\mathbf{2}$ & CC- & 80,0 & 10,6 & 1,1 & 0,71 \\
\hline $\mathbf{3}$ & CC- & 130,0 & 10,3 & 1,3 & 1,03 \\
\hline
\end{tabular}

Realizaram-se análises químicas nas superfícies dos metais depositados antes e após tratamentos térmicos, em todos os corpos de prova, através de espectrômetro de emissão ótica, conforme a norma ASTM E 1086-08.[9] A tabela 2 apresenta as composições químicas dos metais base e do consumível utilizados, conforme certificados de qualidade dos fabricantes.

Tabela 2 - Composições químicas dos metais base e do consumível de soldagem (\%massa).

\begin{tabular}{|c|c|c|c|c|c|c|c|c|}
\hline Componente & $\mathrm{Fe}$ & $\mathrm{Cr}$ & $\mathrm{Al}$ & Si & $\mathrm{Ni}$ & $\mathrm{Zr}$ & Mo & Mn \\
\hline AISI $310-\varnothing 9,5 \mathrm{~mm}$ & 52,18 & 25,01 & 0,00 & 0,06 & 20,11 & 0,00 & 0,35 & 1,93 \\
\hline Kanthal A1 - $\varnothing 4,0 \mathrm{~mm}$ & 68,96 & 23,23 & 7,30 & 0,33 & 0,08 & 0,09 & 0,00 & 0,00 \\
\hline Kanthal A1 - $\varnothing 2,0 \mathrm{~mm}$ & 70,12 & 21,41 & 7,08 & 0,30 & 0,08 & 0,08 & 0,00 & 0,00 \\
\hline
\end{tabular}

Realizou-se tratamento isotérmico a $1150^{\circ} \mathrm{C}$ por 39 dias, totalizando $936 \mathrm{~h}$. O tratamento foi realizado em um forno tipo mufla. Foi tratado 1 conjunto de corpos de prova para cada parâmetro de soldagem utilizado.

Para a preparação das amostras para metalografia, os corpos de prova foram cortados na região da junta soldada. Posteriormente as amostras foram embutidas em resina termofixa de cura à quente (baquelite). Empregou-se o polimento manual convencional utilizando-se lixas d'água (100, 240, 320, 400, 600 e 1000 mesh) com o objetivo de se padronizar o acabamento superficial das amostras. Posteriormente realizou-se o polimento em pano com pasta abrasiva de diamante, de 9, 3 e $1 \mu \mathrm{m}$, nessa sequência.

Foi utilizado o ataque eletrolítico com ácido oxálico 10\%, com tempo aproximado de 90 s e uma tensão de 5V. O equipamento utilizado foi da marca Struers modelo Polectrol. Isto permitiu a caracterização microestrutural das amostras através de microscopia óptica, bem como uma melhor observação no MEV das fases presentes nas camadas oxidadas

As amostras oxidadas foram estudadas utilizando-se difração de raios $X$. Para isto utilizou um difratômetro de raios $X$ da Rigaku, modelo MiniFlex, do LAREX no Departamento de Engenharia Química da Escola Politécnica da Universidade de São Paulo.

\section{RESULTADOS E DISCUSSÃO}

Caracterizou-se os metais de base e as juntas soldadas antes e após o tratamento térmico. A figura 2 apresenta as micrografias da liga Fe-Cr-Al (Kanthal A1). 

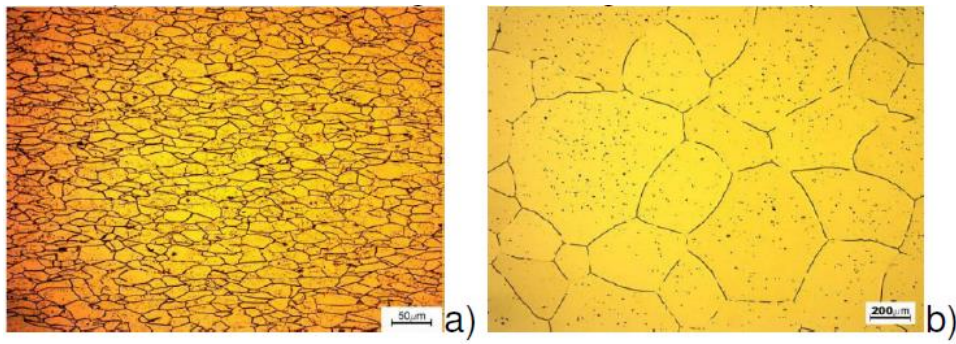

Figura 2 - Metal de base Fe-Cr-Al (Kanthal A1) antes e após tratamento térmico. a) antes do tratamento térmico e b) após tratamento térmico.

A figura 3 apresenta as micrografias o aço inoxidável austenítico AISI 310.
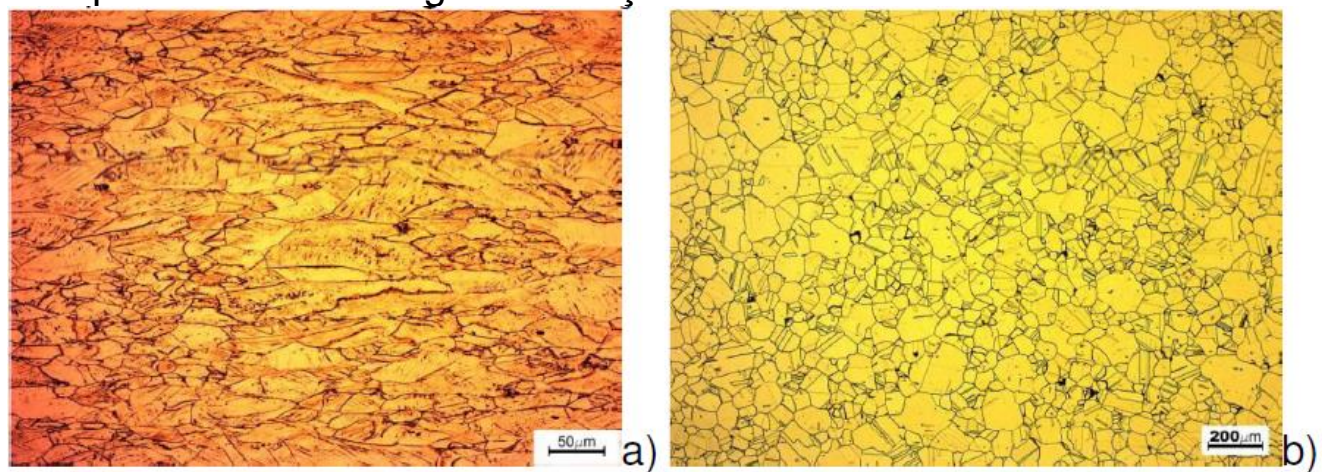

Figura 3 - Metal de base Aço Inoxidável AISI 310 laminado antes e após tratamento térmico. a) antes do tratamento térmico e b) após tratamento térmico.

A figura 4 apresenta as análises macrográficas dos corpos de prova soldados.
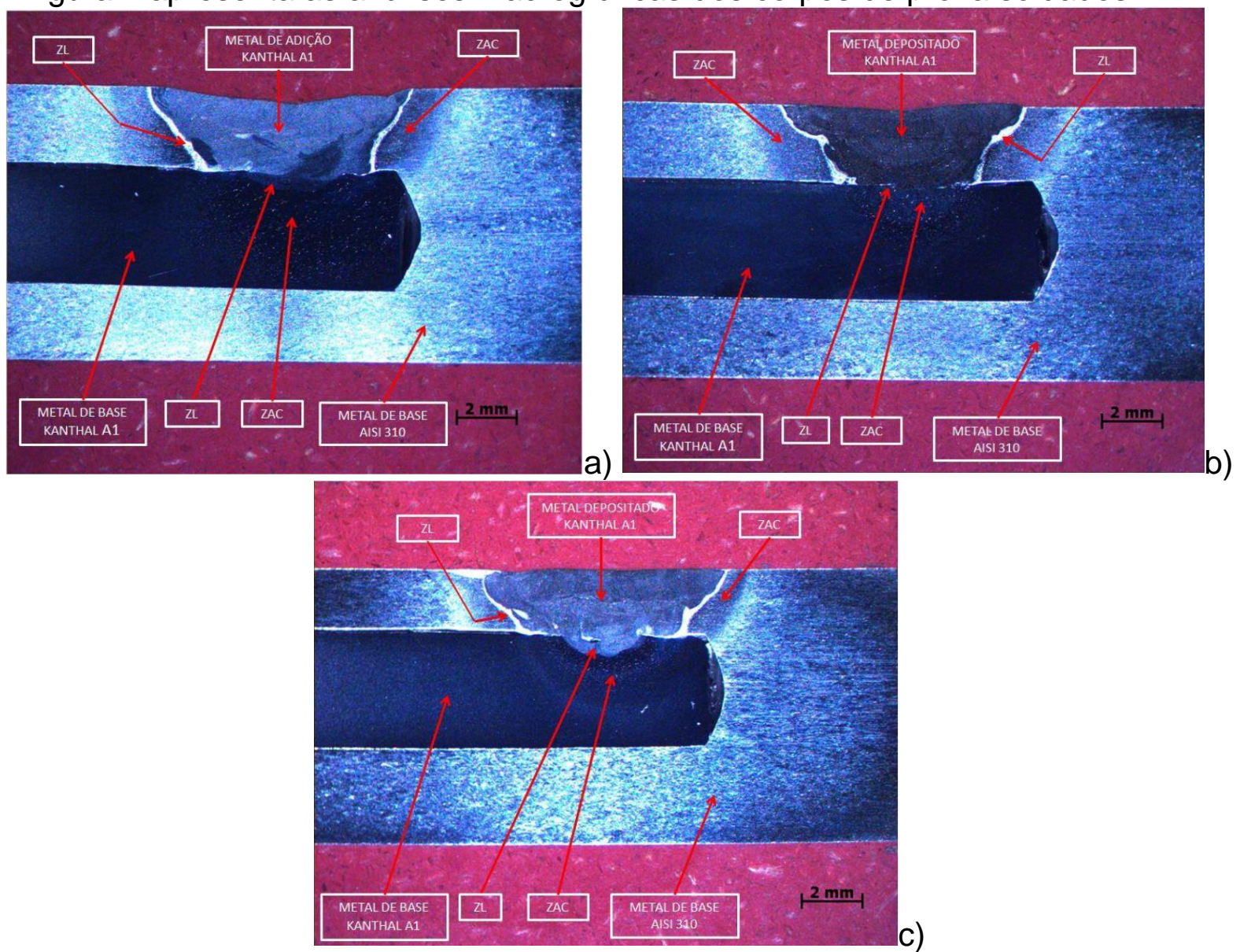

Figura 4 - Macrografias dos corpos de prova soldados. a) CP1, b) CP2 e c) CP3. 
Nas figuras 2, 3 e 4 observa-se a ausência de porosidades antes do tratamento térmico.

Observa-se que ambos os metais base antes do tratamento térmico apresentam grãos alongados. Esta microestrutura é típica de metais base conformados termomecanicamente como no caso da liga Fe-Cr-Al (Kanthal A1) que foi trefilada e do aço inoxidável austenítico AISI 310 que foi laminado.

Observa-se após tratamento térmico, a recristalização dos grãos alongados para equiaxiais. A temperatura de tratamento térmico escolhida, $1150^{\circ} \mathrm{C}$, é aproximadamente a temperatura de solubilização do aço inoxidável 310 .

A figura 5 apresenta as micrografias das juntas dissimilares Kanthal A1/310, soldadas antes do tratamento térmico.

Não observam-se poros nos metais base nem nos metais depositados antes do tratamento térmico.
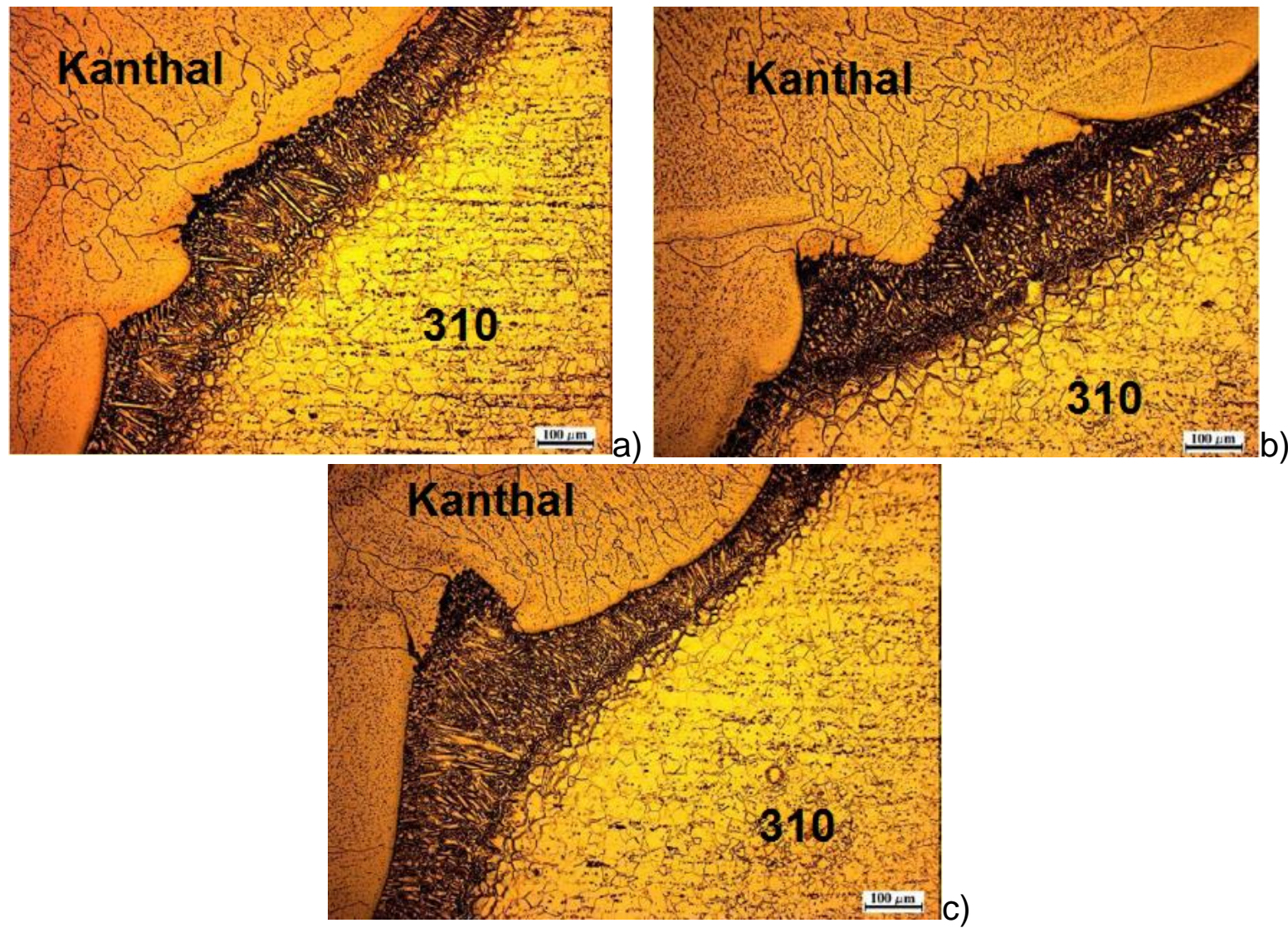

Figura 5 - Caracterização micrográfica das juntas soldadas antes do tratamento térmico. Detalhe das juntas dissimilares Kanthal A1/310. a) CP1 b) CP2 e c) CP3.

A figuras 6 apresenta a análise micrográfica de região próxima à zona de ligação entre o metal base Fe-Cr-Al (Kanthal A1) e o metal depositado da junta soldada do CP1 antes e após tratamento térmico. 

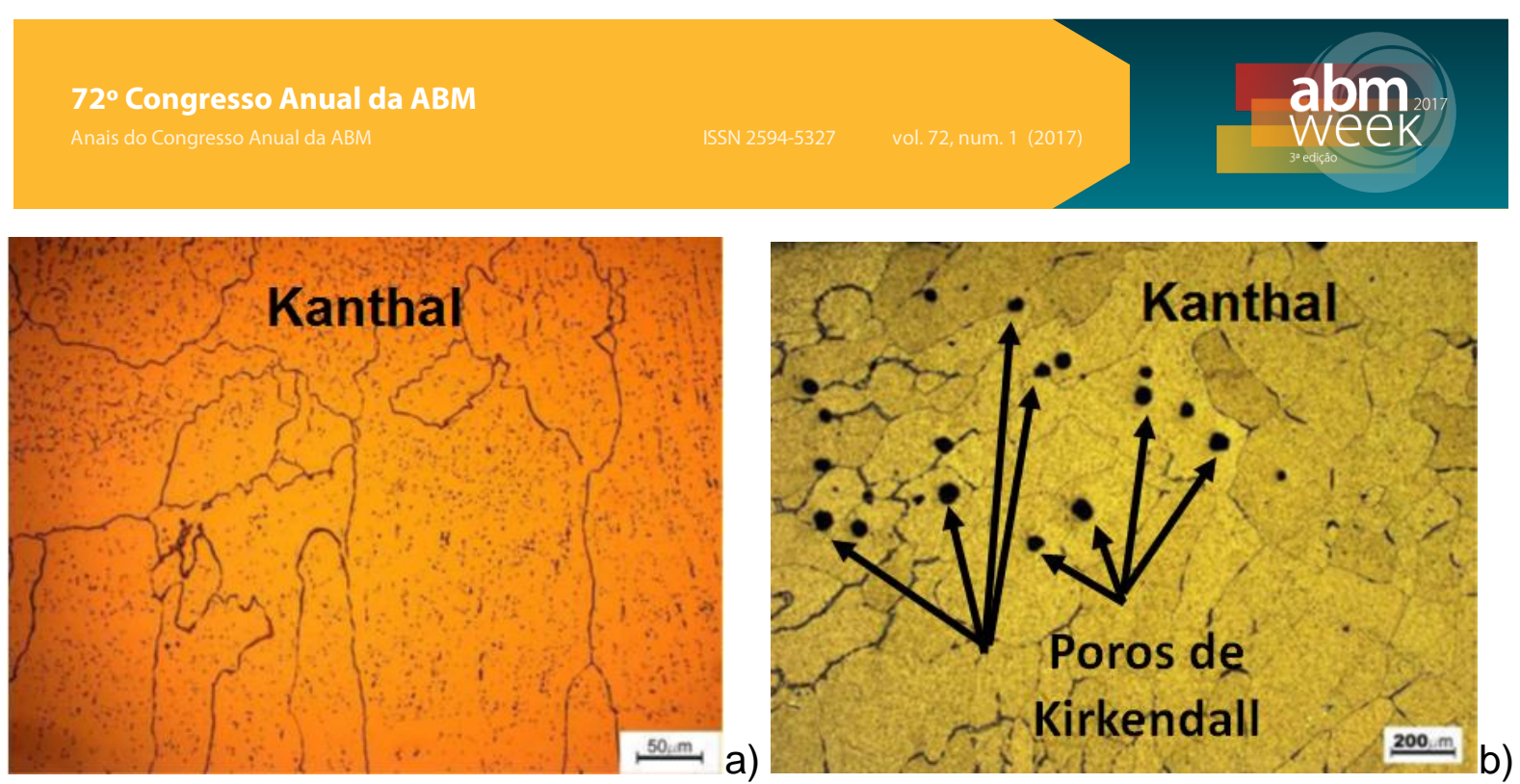

Figura 6 - Região próxima à zona de ligação entre o metal base Fe-Cr-Al (Kanthal A1) e o metal depositado do CP1 antes e após tratamento térmico.

a) antes do tratamento térmico e b) após tratamento térmico.

Observa-se a formação de grande quantidade de poros nos metais depositados, nas regiões próximas às zonas de ligação entre os metais base AISI 310 e os metais depositados, nos três corpos de prova soldados após o tratamento térmico.
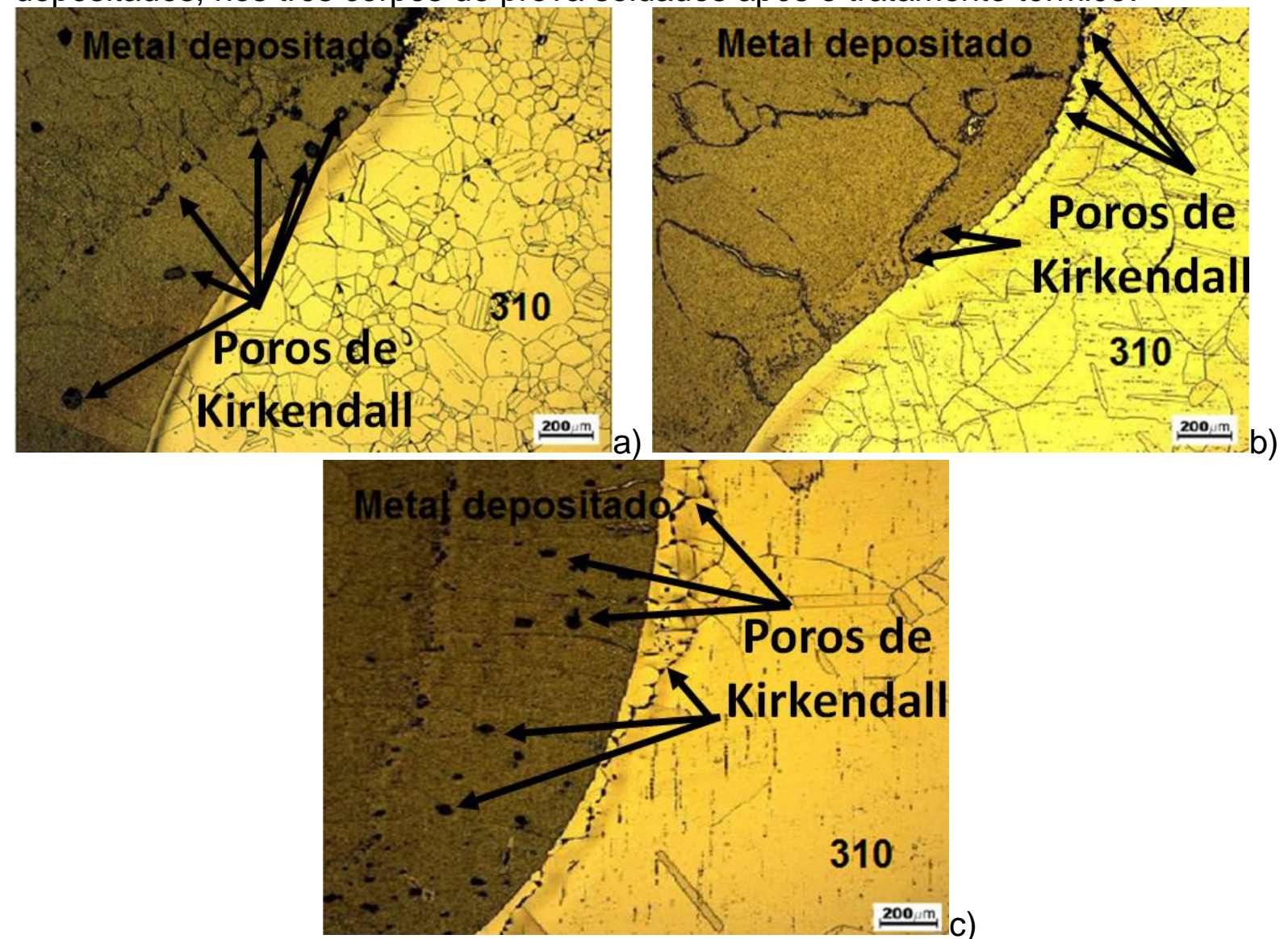

Figura 7 - Caracterização micrográfica das juntas soldadas após o tratamento térmico. a) CP1 b) CP2 e c) CP3.

A figura 8 apresenta a análise micrográfica de região próxima à zona de ligação entre o metal base aço inoxidável austenítico AISI 310 e o metal depositado da junta soldada do CP1 antes e após tratamento térmico. 

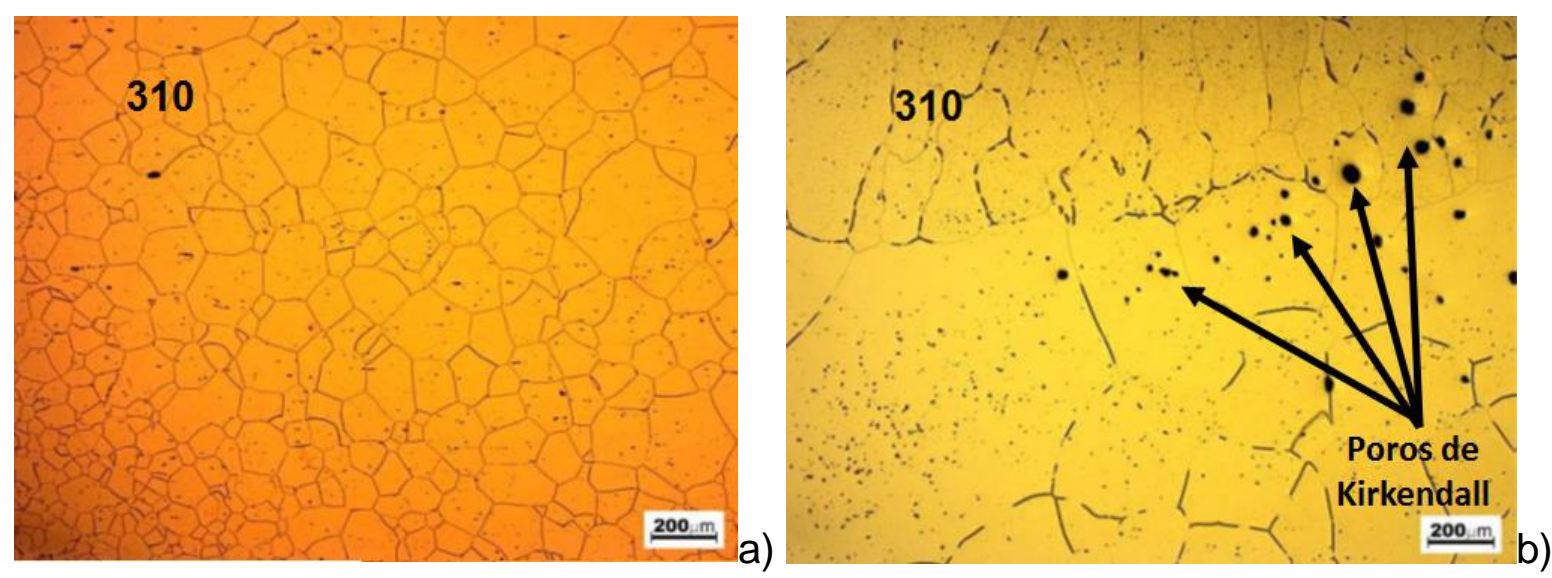

Figura 8 - Região próxima à zona de ligação entre o metal base aço inoxidável austenítico AISI 310 e o metal depositado do CP1 antes e após tratamento térmico.

a) antes do tratamento térmico e b) após tratamento térmico.

Observam-se precipitados nos contornos de grão e porosidades, tanto no metal depositado como no metal base próximo à linha de fusão. Observou-se também o aumento do tamanho de grão.

Analisou-se a composição química nas superfícies dos metais depositados dos 3 corpos de prova antes e após tratamento térmico. Os resultados são apresentados na tabela 3.

Tabela 3 - Composição química dos metais base, consumível de soldagem e metais depositados antes a após tratamento térmico (\%massa).

\begin{tabular}{|c|c|c|c|c|c|}
\hline Componente & $\mathbf{F e}(+/-\mathbf{0 , 0 5})$ & $\mathbf{C r}(+/-\mathbf{0 , 0 7})$ & $\mathbf{A l}(+/-\mathbf{0 , 0 8})$ & $\mathbf{S i}(+/-\mathbf{0 , 0 1})$ & $\mathbf{~ N i}(+/-\mathbf{0 , 0 5})$ \\
\hline AISI $\mathbf{3 1 0}$ - $\boldsymbol{\varnothing 9 , 5 ~} \mathbf{~ m m}$ & 52,18 & 25,01 & 0,00 & 0,06 & 20,11 \\
\hline Kanthal A1 - $\mathbf{4 , 0} \mathbf{~ m m}$ & 68,96 & 23,23 & 7,30 & 0,33 & 0,08 \\
\hline Kanthal A1 - $\mathbf{~ 2 , 0 ~} \mathbf{~ m m}$ & 70,12 & 21,41 & 7,08 & 0,30 & 0,08 \\
\hline Metal Depositado CP1 antes do ToTo & 63,69 & 23,09 & 4,46 & 0,32 & 7,93 \\
\hline Metal Depositado CP1 após o ToTo & 63,24 & 23,25 & 4,41 & 0,31 & 8,29 \\
\hline Metal Depositado CP2 antes do ToTo & 65,99 & 22,66 & 5,40 & 0,30 & 5,22 \\
\hline Metal Depositado CP2 após o ToTo & 63,56 & 23,62 & 3,77 & 0,31 & 8,21 \\
\hline Metal Depositado CP3 antes do ToTo & 65,31 & 22,99 & 5,04 & 0,30 & 6,09 \\
\hline Metal Depositado CP3 após o ToTo & 64,35 & 23,31 & 3,89 & 0,32 & 7,27 \\
\hline
\end{tabular}

Analisando-se a tabela 3, observa-se a diminuição do teor de alumínio nos corpos de prova soldados após o tratamento térmico, independente da energia de soldagem utilizada no procedimento.

Desta forma tornou-se interessante a análise dos óxidos formados nas superfícies dos corpos de prova.

A figura 9 apresenta o difratograma de raios $\mathrm{X}$ da superfície do metal depositado do $\mathrm{CP} 1$ (liga $\mathrm{Fe}-\mathrm{Cr}-\mathrm{Al}$ ) após tratamento isotérmico a $1150^{\circ} \mathrm{C}$ por $936 \mathrm{~h}$ ao ar. 


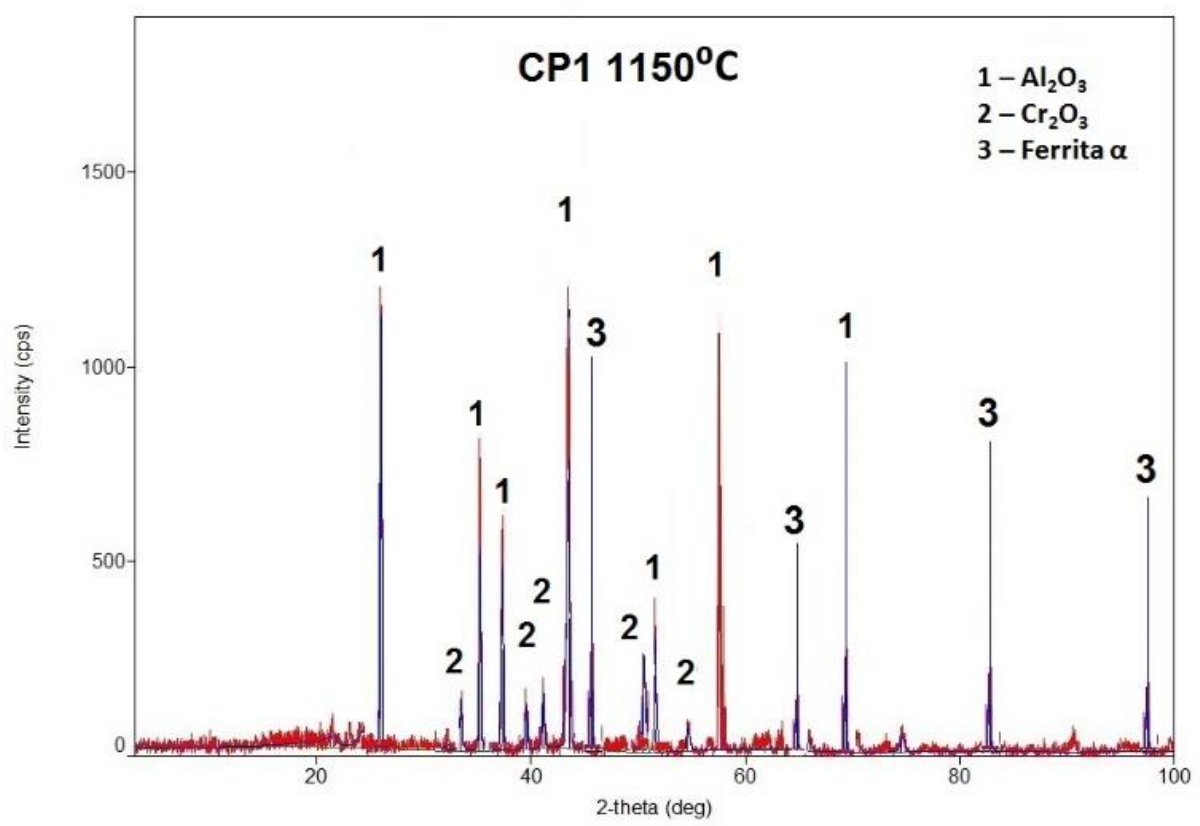

Figura 9 - Difratograma da superfície oxidada do metal depositado do CP1 após tratamento isotérmico a $1150^{\circ} \mathrm{C}$ por $936 \mathrm{~h}$ ao ar.

Observam-se picos bem definidos de ferrita e a presença dos óxidos protetivos $\mathrm{Al}_{2} \mathrm{O}_{3}$ e $\mathrm{Cr}_{2} \mathrm{O}_{3}$. A camada de óxidos protetivos é formada principalmente de $\mathrm{Al}_{2} \mathrm{O}_{3}$.

A difração de raios-X é uma técnica bastante útil para análise de depósitos em superfícies metálicas, como no caso de camadas de óxido formadas a altas temperaturas. [10]

A figura 10 apresenta a micrografia, a análise química qualitativa e a caracterização dos óxidos formados na superfície do metal depositado (liga Fe-Cr-Al) após tratamento isotérmico a $1150^{\circ} \mathrm{C}$ por $936 \mathrm{~h}$ ao ar.

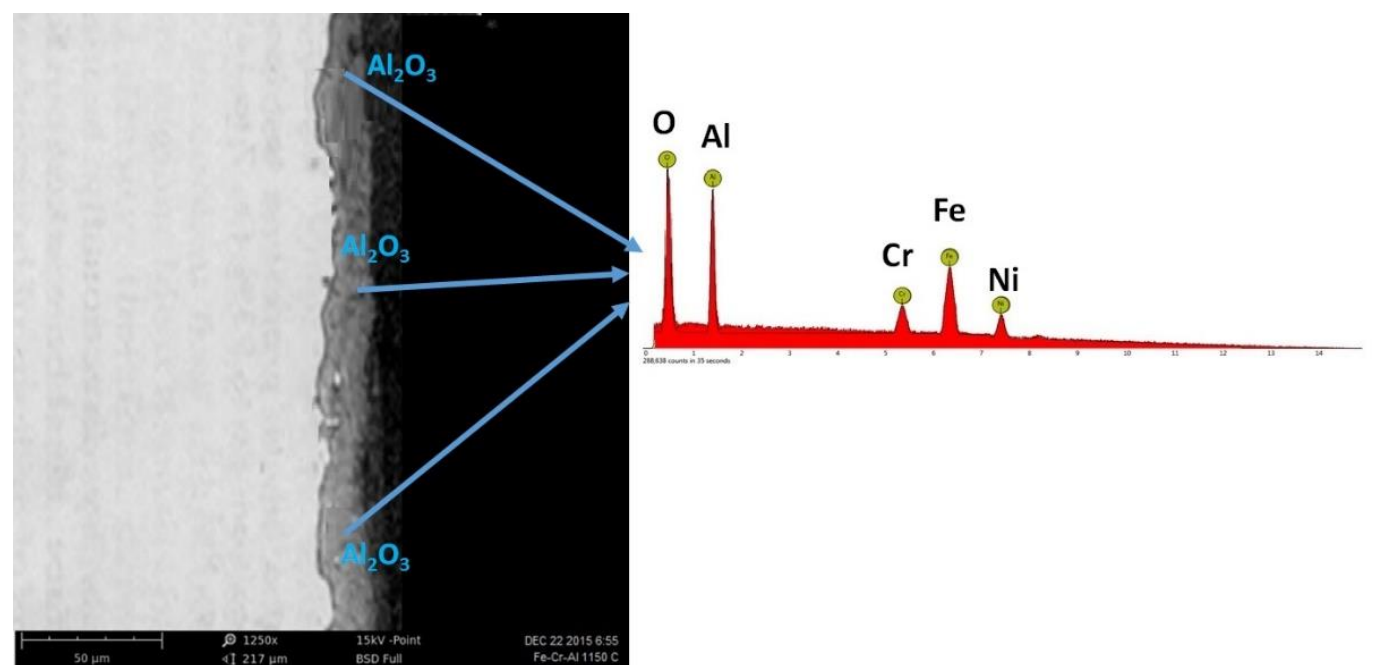

Figura 10 - Micrografia e EDS do corte da amostra oxidada do metal depositado do CP1 após tratamento isotérmico a $1150^{\circ} \mathrm{C}$ por $936 \mathrm{~h}$ ao ar.

Utilizando-se as informações obtidas no difratograma e a análise quantitativa obtida através de microscopia eletrônica de varredura com EDS acoplado, foi possível concluir que camada de óxidos protetivos formada na superfície dos metais depositados da liga Fe-Cr-Al, após ensaio isotérmico a $1150 \stackrel{\circ}{\mathrm{C}}$ por $936 \mathrm{~h}$ ao ar, é formada principalmente de $\mathrm{Al}_{2} \mathrm{O}_{3}$. 


\section{CONCLUSÃO}

A formação de poros nos metais depositados ocorre após o tratamento térmico, uma vez que no estado como soldado os mesmos não foram observados.

O teor de alumínio variou significativamente nos metais depositados após o tratamento térmico.

As camadas de óxidos protetivos observadas nas superfícies dos metais depositados é formada, principalmente, de $\mathrm{Al}_{2} \mathrm{O}_{3}$.

Os resultados obtidos sugerem que os poros observados nas juntas soldadas após tratamento térmico sejam poros de Kirkendall devido à rápida difusão do alumínio do metal depositado para o aço inoxidável austenítico AISI 310 bem como para a superfície oxidada para formação de camada protetora de $\mathrm{Al}_{2} \mathrm{O}_{3}$.

\section{Agradecimentos}

À SMT - Sandvik Materials Technology, representada pelo caro colega politécnico Fausto Camargo e pelo caro amigo Luiz Gobbis, por acreditar neste projeto e pela doação do metal base e do consumível de soldagem bem como por sempre apoiar a Escola Politécnica da Universidade de São Paulo quando existe o interesse em realizar-se estudos envolvendo ligas resistentes à corrosão.

À Prax Air representada pelos caros colegas Marcos Lobato e Jeferson Costa, por acreditar neste projeto e pela doação dos gases de proteção para a soldagem e do ar sintético para os ensaios de oxidação bem como por sempre apoiar a Escola Politécnica da Universidade de São Paulo quando existe o interesse em realizar-se estudos envolvendo gases especiais.

\section{REFERÊNCIAS}

1. NAKAJIMA, HIDEO. The discovery and acceptance of Kirkendall effect. JOM

2. SMALLMAN, R.E.; BISHOP, R.J. Modern Physical Metallurgy and Materials Engineering, 6. ed., p. 172-176.

3. SEITZ, F. On the porosity observed on Kirkendall effect. Acta Metalutgica, V.1, p.355-369. 1953

4. ALDINGER, F. Controlled porosity by an extreme Kirkendall effect. Acta Metalurgica V.22, p.923-928. 1974

5. HOGLUND, L; AGREN, J.Analisys of the Kirkendall effect, marker migration and pore formation. Acta Materiallia V.49, p.1311-1317. 2001

6. STRANDLUND, H; LARSSON, H. Prediction of Kirkendall shift and porosity in a binary and ternary diffusion couples. Acta Materialia, V.52, p. 4695-4703. 2004

7. ASTM SPECIALTY HANDBOOK, Heat-resistant materials, p. $074-078, \mathrm{OH}, \mathrm{USA}$, 1997.

8. CASE, S. L.; VAN HORN, K. R.; Aluminium in iron and steel, 477 pgs, New York, 1953.

9. ASTM E1086-08: Standard Test Method for Optical Emission Vacuum Spectrometric Analysis of Stainless Steel by the Point-to-Plane Excitation Technique, ASTM International, West Conshohocken, PA, EUA, 2008.

10. CULLITY, B. D. Chemical Analysis by X-Ray Diffraction, Elements of X-Ray Diffraction, 2a Ed., p. 397-420, 1978. 